\title{
Experimental Analysis of Mechanical Properties of the Unconventional Sand-Plastic Bricks Using Statistical Method
}

\author{
Ritesh Bhat ${ }^{1{ }^{* *},}$ Raghavendra Kamath C. ${ }^{1}$, Nanjangud Mohan ${ }^{1}$, Nithesh Naik ${ }^{1}$, Prashant Mulimani ${ }^{2}$ \\ and Koh Mun $\mathrm{Fei}^{3}$
}

${ }^{I}$ Department of Mechanical and Manufacturing Engineering, Manipal Academy of Higher Education, Manipal, India 576104

${ }^{2}$ Department of Mechanical Engineering, SKSVMA College of Engineering and Technology, Lakshmeswar, Gadag, India, 582116

${ }^{3}$ Senior Project Engineer, Kota Menara Ufuk Sendirian Berhad, Klang, Selangor, Malaysia 41200

Received 12 August 2018; Accepted 24 November 2019

\begin{abstract}
Plastic wastes found in high percentage in the municipal solid wastes (MSW) have attracted consideration recently due to environmental safety issues. The plastic-wastes used as one of the raw-materials in the processing of construction related products, bricks in particular, is a new way of waste utilisation. Plastics are in use in several ways, right from the drinking bottles to household items, which in turn converts to waste once the functionality ends. Since the plastics, thermoplastics in particular are not biodegradable, one optimum way of using these plastic-wastes are essential for solving this problem of their increase in number. The main aim of this investigation is to comprehend the effects of plastic wastes (polyethylene terephthalate and high-density polyethylene) on the mechanical properties of bricks. The preparation of the brick had $10 \%$, $25 \%$ and $40 \%$ of plastic wastes. The mixture of sand and plastic wastes, as per their percentage by weights, were placed in the preheated mould with $700{ }^{\circ} \mathrm{C}$ temperature, holding them at the peak temperature for 15 minutes. The molten mixture was poured in the fabricated mould and allowed to cool down. The prediction from the optimized response plot along with the real-time fabricating and testing of sand-plastic brick infers that the brick comprising $25 \%$ by weight of plastic yields the best sand plastic brick, exhibiting an average compressive strength of $133 \mathrm{MPa}$, which implies that it can withstand $72.59 \%$ more compressive stress than the commercially available Indian FCBs.
\end{abstract}

Keywords: recycling plastic wastes, sand waste, bricks, mechanical properties, response surface method

\section{Introduction}

One of the major developmental goal of the world is the promotion of sustainability and environmental safety. Several countries in the world today are tackling with the appropriate management and disposal of its municipal solid waste $(\mathrm{MCW})$, in particular the plastic waste (PW). The general existing methods of disposal in the current trend are incineration, landfilling, haphazard littering, which imposes negative effect on the human health and the surrounding environment. The current disposal system is gradually choking the atmosphere and the filling the surroundings with plastics. The major contributor the plastic wastes are the polyethylene trephalate (PET) and the high-density polyethylene (HDPE), utilized in most of the daily-use items. Every day, a large amount of items made up completely or partially of the said plastic is utilized, which, eventually, end up in accumulated MSW. The major concern is that the said plastics are not biodegradable and hence does not break into particles absorbable by nature. In simple words, plastics are one such culprit that accommodates to a high percentage for environmental pollution [1].

Recycling the plastics is the quick need in present scenario in order to close the material-loops, in turn to maintain the natural resources. The rate of spread of the plastic wastes in environment is much higher than the rate at which they are

*E-mail address: ritesh.bhat@manipal.edu

ISSN: 1791-2377 @ 2020 School of Science, IHU. All rights reserved.

doi:10.25103/jestr.132.02 been recycled. MSW contributes to around $80 \%$ by fraction of the global plastic wastes, which includes the thermoplastics used for this study. The various mechanical along with the rheological tests have shown that the possibilities of using plastic wastes as raw materials. The work done by authors [2] proves that the applicability of the plastic wastes for the new product as per the need shall be assessed. One of the significant environmental solution to the increasing problem of the plastic wastes are the mechanical recycling. The authors [3] investigated thoroughly the life-cycle environmental effects of mechanical plastic recycling system.

The collected wastes from various source in China were processed and sent back to market. In comparison to the composite and 'new' plastic materials, the mechanically recycled plastics proves to be an excellent choice in most environmental scenarios. The construction industrial sector contributes significantly to the global economy. In India alone, the sector generates about $8 \%$ and in European Union (EU), it generates nearly $10 \%$ of gross domestic product (GDP). Like any industry, construction sector also generates wastes, which has no particular composition. Most of these wastes are typically disposed to the landfills, with no intention of re-use or recovery. One such disposed construction material is the excessively procured sand. Such wastes generate the significant environmental and economic concern [4]. The recycled sand as per the author's [5] experimental work has proved to be a better alternative as raw materials in construction industry than the conventional mixing elements in terms of the mechanical, microstructural and physical properties of the final product. An extensive literature 
reviewed by the authors [6] has shown that the recycled aggregates from the construction wastes in comparison to the conventional and natural aggregates, could be used as raw materials in the construction materials.

Fired clay bricks (FCBs) until date remains to be the oldest and ecological construction material, as natural raw material viz., clay, water and sand contributes to its composition. The conventional bricks exhibit excellent mechanical properties and proves best to be used for the construction [7]. With the demand for construction development due to rapid global urbanization, the demand for the bricks is increasing. The industries, manufacturing the fired clay bricks, contributes towards the air pollution largely. Hence, an increase in the demand of bricks implies the increase in the air pollution, which in turn increases the health problems [8]. Table. 1 represents the minimum average compressive strength of Indian FCBs as per IS standards[9], [10].

Table 1. Classification of Indian fired clay bricks

\begin{tabular}{|c|c|}
\hline Class Designation & $\begin{array}{c}\text { Minimum Average } \\
\text { Compressive Strength } \\
(\mathrm{MPa})\end{array}$ \\
\hline $\begin{array}{l}35 \text { (Highest class of } \\
\text { common FCB) }\end{array}$ & 35 \\
\hline $\begin{array}{c}45 \text { (Highest class of heavy } \\
\text { duty FCB) }\end{array}$ & 45 \\
\hline
\end{tabular}

Researchers [11] investigated the mechanical property in term of the compressive strength of the fabricated plastic bottled blocks of concrete. The work makes use of the waste $500 \mathrm{ml}$ plastic bottle for the investigation purpose. The study showed that there was a $57 \%$ rise in the compressive strength when compared to the available commercial concrete blocks. Another study, focused on using the plastic wastes, obtained from used cables and footwear in making of plastic mixed building material in form of lightweight concrete. The plastic used here was the only aggregating material. The investigative work proved that the proportion of plastic added to the mixture has a significant effect. The work also depicted that the thermos-technical properties improves with plastic addition [12]. Developed by Box in the 1950's the response surface method or RSM is an excellent tool that very well combines the experimental design with the statistical method. The regression equation obtained by using RSM is generally used to fit in the relationship between the terms (input parameters or affecting factors) and the optimal level for each factor could be obtained by synthesizing the significance of the response (output parameter or affected factor) [13], [14].

\section{Experimental Methods and Materials}

The experiment comprised of using sand along with the thermoplastic wastes made up of PET and HDPE. The thermoplastics were finely chopped and dry-mixed in random proportion. This mixture was then dry-mixed with the waste sand obtained from the construction zone in three different fixed proportion of plastic waste by percentage weight. The preheated furnace was made use, to house the prepared sandplastic mixture. The mixture of sand and plastic wastes, as per their percentage by weights, were placed in the preheated mould with $700{ }^{\circ} \mathrm{C}$ temperature, holding them at the peak temperature for 15 minutes. The molten compound was poured into the clay brick mould and allowed to cool down before demoulding. Three specimens of $230 \times 115 \times 75 \mathrm{~mm}$ and three specimens of $55 \times 10 \times 10 \mathrm{~mm}$ were made out of each type of $B_{a}, B_{b}$ and $B_{c}$.

Table. 2 depicts the composition of moulded compounds. All prepared specimen, were kept in laboratory, exposed to ambient temperature for a time-period of 15 days. Further, the experimental analysis were carried out using the response surface method (RSM) on $B_{a}, B_{b}$ and $B_{c}$ bricks. Fig. 1 represents the block diagram, depicting the followed methodology for processing the sand-plastic (SP) bricks. The conduction of compressive strength test on the specimen followed 'ASTM C67 standard of testing bricks and structural clay tile'. Charpy test without notch, using '300J charpy impact testing equipment' was been used to conduct the impact test. 'Digital hardness tester by ECO instruments' was in use to measure the Rockwell hardness of the bricks.

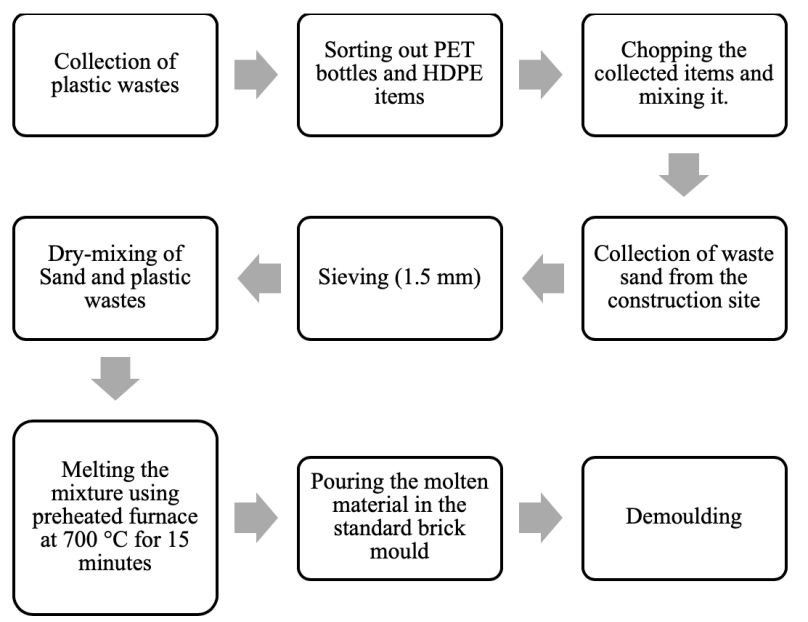

Fig. 1. Methodology flowchart

Table 2. Composition of moulded compounds

\begin{tabular}{|c|c|c|c|}
\hline \multirow[t]{2}{*}{ Raw materials } & \multicolumn{3}{|c|}{$\begin{array}{c}\text { Composition of moulded } \\
\text { compounds in percentage by } \\
\text { weight }\end{array}$} \\
\hline & $\begin{array}{c}\text { Type } A \\
\text { brick } \\
\left(B_{a}\right) \\
\end{array}$ & $\begin{array}{l}\text { Type B } \\
\text { brick } \\
\left(B_{b}\right)\end{array}$ & $\begin{array}{c}\text { Type C } \\
\text { brick } \\
\left(\mathbf{B}_{c}\right)\end{array}$ \\
\hline $\begin{array}{c}\text { Plastic waste } \\
\text { comprising PET and } \\
\text { HDPE }\end{array}$ & 10 & 25 & 40 \\
\hline $\begin{array}{l}\text { Waste sand from } \\
\text { construction site }\end{array}$ & 90 & 75 & 60 \\
\hline
\end{tabular}

While using the RSM, the two input parameters of two levels were selected, one being the percentage of plastic waste in the bricks and the second being the percentage of sand waste (SW) being used in the bricks. The response parameters for the experimental work is the compressive strength $\left(\mathrm{N} / \mathrm{mm}^{2}\right)$, impact strength (KCU) and the Rockwell hardness (HB).

The linear +interaction equation was obtained to comprehend the effect of the parameters in the bricks and to estimate the optimum amount of plastic waste $(\% \mathrm{P})$ and sandwaste $(\% \mathrm{~S})$ combination to obtain the bricks exhibiting the said mechanical properties to the currently available fired clay bricks in India. Analysis of variance (ANOVA) was carried out with $95 \%$ confidence value. Table 3 represents the details of the terms and respective levels, used in the experimental analysis. 
Table 3. Details of the terms and respective levels

\begin{tabular}{c|c|c|c}
\hline \multirow{2}{*}{ S. No } & Parameters & \multicolumn{2}{|c}{ Levels } \\
\cline { 3 - 4 } & & $\mathbf{- 1}$ & $\mathbf{1}$ \\
\hline 1 & \% Plastic Waste & 10 & 40 \\
2 & \% Sand Waste & 40 & 90 \\
\hline
\end{tabular}

The two input parameters of two levels selected for the experimental work are the percentage by weight of PW in SP bricks and the percentage by weight of SW in the SP bricks. The response parameters for the experimental work is the compressive strength (MPa), impact strength (KCU) and the Rockwell hardness (HB)

The 'linear + interactive' regression equation was obtained to comprehend the effect of the parameters in the bricks and to estimate the optimum percentage by weight of plastic waste $(\% \mathrm{P})$ and sand waste $(\% \mathrm{~S})$ to obtain the SP bricks exhibiting the said mechanical properties to the currently available fired clay bricks in India. Analysis of variance (ANOVA) was carried out with $95 \%$ confidence value. Table 3 represents the details of the parameters and respective levels, used in the experimental analysis.

\section{Results and Discussion}

Table. 4 depicts the experimental analysis (EA) results of the effect of parameters on the compressive strength (CS). The $p$ value of the interaction between two terms and percentage by weight of plastic waste $(\% \mathrm{P})$ holds the statistical significance over the compressive strength. Eq. 1 represents the regression equation for the same.

$$
C S=132.067-2.047(\% P)+51.533(\% P \% S)
$$

Table 4. Compressive strength - EA results

\begin{tabular}{c|c|c|c|c|c|c|c}
\hline Source & DF & Seq SS & Contribution & Adj SS & Adj MS & F & P \\
\hline Model & 2 & 5336.50 & $99.81 \%$ & 5336.50 & 2668.25 & 1615.57 & 0.000 \\
Linear & 1 & 25.13 & $0.47 \%$ & 25.13 & 25.13 & 15.22 & 0.008 \\
\%P & 1 & 25.13 & $0.47 \%$ & 25.13 & 25.13 & 15.22 & 0.008 \\
2-Way Interaction & 1 & 5311.37 & $99.34 \%$ & 5311.37 & 5311.37 & 3215.91 & 0.000 \\
\%P*\%S & 1 & 5311.37 & $99.34 \%$ & 5311.37 & 5311.37 & 3215.91 & 0.000 \\
Error & 6 & 9.91 & $0.19 \%$ & 9.91 & 1.65 & & \\
Total & 8 & 5346.41 & $100.00 \%$ & & & & \\
\hline
\end{tabular}

Table 5 represents the experimental analysis (EA) results displaying the effect of parameters on the impact strength (IS). The $p$ value of the interaction between two terms and percentage by weight of plastic waste $(\% \mathrm{P})$ holds the statistical significance over the impact strength. Eq. 2 represents the regression equation for the same.

$$
I S=49.36-4.44(\% P)+7.99(\% P \% S)
$$

Table 5. Impact strength - EA results

\begin{tabular}{c|c|c|c|c|c|c|c}
\hline Source & DF & Seq SS & Contribution & Adj SS & Adj MS & F-Value & P-Value \\
\hline Model & 2 & 245.83 & $72.62 \%$ & 245.83 & 122.92 & 7.96 & 0.021 \\
Linear & 1 & 118.22 & $34.92 \%$ & 118.22 & 118.22 & 7.65 & 0.033 \\
\%P & 1 & 118.22 & $34.92 \%$ & 118.22 & 118.22 & 7.65 & 0.033 \\
2-Way Interaction & 1 & 127.61 & $37.70 \%$ & 127.61 & 127.61 & 8.26 & 0.028 \\
\%P*\%S & 1 & 127.61 & $37.70 \%$ & 127.61 & 127.61 & 8.26 & 0.028 \\
Error & 6 & 92.68 & $27.38 \%$ & 92.68 & 15.45 & & \\
Total & 8 & 338.51 & $100.00 \%$ & & & & \\
\hline
\end{tabular}

Table 6 represents the experimental analysis (EA) results displaying the effect of terms on the Rockwell hardness (HB). The $p$ value of the interaction between two terms and percentage by weight of plastic waste $(\% \mathrm{P})$ holds the statistical significance over the Rockwell hardness. Eq. 3 represents the regression equation for the same.

$H B=26.80-1.27(\% P)+6.17(\% P \% S$

Table 6. Impact strength - EA results

\begin{tabular}{c|c|c|c|c|c|c|c}
\hline Source & DF & Seq SS & Contribution & Adj SS & Adj MS & F-Value & P-Value \\
\hline Model & 2 & 85.682 & $58.37 \%$ & 85.682 & 42.841 & 4.21 & 0.072 \\
Linear & 1 & 9.627 & $6.56 \%$ & 9.627 & 9.627 & 0.95 & 0.368 \\
\%P & 1 & 9.627 & $6.56 \%$ & 9.627 & 9.627 & 0.95 & 0.368 \\
2-Way Interaction & 1 & 76.056 & $51.81 \%$ & 76.056 & 76.056 & 7.47 & 0.034 \\
\%P*\%S & 1 & 76.056 & $51.81 \%$ & 76.056 & 76.056 & 7.47 & 0.034 \\
Error & 6 & 61.107 & $41.63 \%$ & 61.107 & 10.184 & & \\
Total & 8 & 146.789 & $100.00 \%$ & & & & \\
\hline
\end{tabular}

Fig. 2 represents the optimal response plots, predicting the best value for compressive strength (CS) obtainable to be $132.07 \mathrm{MPa}$. The predicted value shows the $\% \mathrm{PW}$ to be $25 \%$ and $\% \mathrm{~S}$ to be $75 \%$. The bricks manufactured at the predicted values, when measured proved to have an average compressive strength of $133 \mathrm{MPa}$. Hence, the theoretically predicted value matches the experimental value with a minute 
and negligible error of $0.007 \%$. One of the brick made with this combination is as shown in Fig. 3.

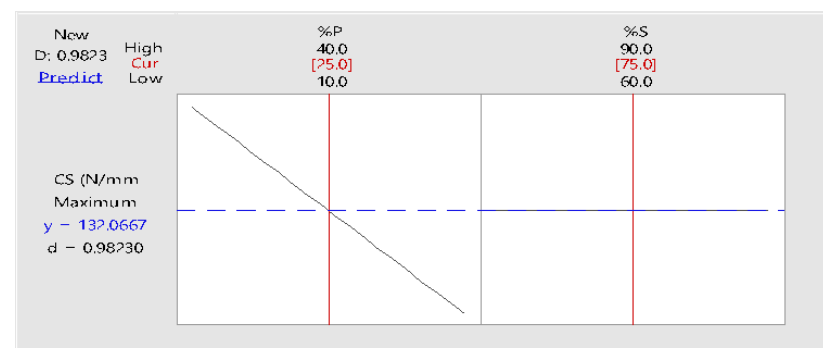

Fig. 2. Optimum response plot for compressive strength

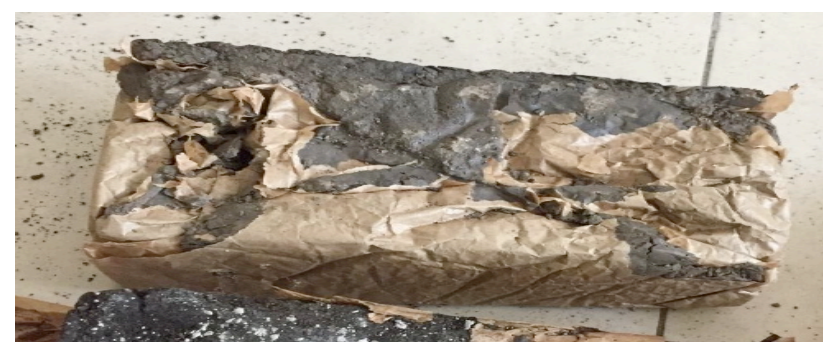

Fig. 3. SP brick with $25 \%$ by weight of $\mathrm{PW}$

\section{Conclusion}

Experimental analysis shows that sand-plastic bricks are one of the best ways to recycle both plastic wastes and constructional sand wastes, addressing the growing challenge of increasing wastes in terms of plastics in the environment. It is also an observation that the percentage by weight of plastic in the sand plastic is the most significant factor. The prediction from the optimized response plot along with the real-time fabricating and testing of sand-plastic brick infers that the brick comprising $25 \%$ by weight of plastic yields the best sand plastic brick, exhibiting an average compressive strength of $133 \mathrm{MPa}$, which implies that it can withstand $72.59 \%$ more compressive stress than the commercially available Indian FCBs.

This is an Open Access article distributed under the terms of the Creative Commons Attribution License

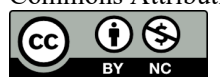

\section{References}

[1] J. K. Appiah, V. N. Berko-Boateng, and T. A. Tagbor, "Use of waste plastic materials for road construction in Ghana," Case Stud. Constr. Mater., vol. 6, pp. 1-7, 2017.

[2] H. Dahlbo, V. Poliakova, V. Mylläri, O. Sahimaa, and R. Anderson, "Recycling potential of post-consumer plastic packaging waste in Finland," Waste Manag., vol. 71, pp. 52-61, 2018.

[3] F. Gu, J. Guo, W. Zhang, P. A. Summers, and P. Hall, "From waste plastics to industrial raw materials: A life cycle assessment of mechanical plastic recycling practice based on a real-world case study," Sci. Total Environ., vol. 601-602, pp. 1192-1207, 2017.

[4] A. Seco, J. Omer, S. Marcelino, S. Espuelas, and E. Prieto, "Sustainable unfired bricks manufacturing from construction and demolition wastes," Constr. Build. Mater., vol. 167, pp. 154-165, 2018.

[5] M. Stefanidou, E. Anastasiou, and K. Georgiadis Filikas, "Recycled sand in lime-based mortars," Waste Manag., vol. 34, no. 12, pp. 2595-2602, 2014.

[6] R. Cardoso, R. V. Silva, de J. Brito, and R. Dhir, "Use of recycled aggregates from construction and demolition waste in geotechnical applications: A literature review," Waste Manag., vol. 49, pp. 131$145,2016$.

[7] O. Kizinievi, V. Kizinievi, I. Pundiene, and D. Molotokas, "ScienceDirect Eco-friendly fired clay brick manufactured with agricultural solid waste," Arch. Civ. Mech. Eng., vol. 8, pp. 1156-
$1165,2018$.

[8] A. D. Bhanarkar, D. G. Gajghate, and M. Z. Hasan, "Assessment of air pollution from small scale industry," Environ. Monit. Assess., vol. 80 , no. 2, pp. 125-133, 2002.

[9] Indian Standards, "IS 1077 (1992): Common Burnt Clay Building Bricks -Specification," 1992.

[10] Indian Standards, "IS 2180 (1988): Heavy Duty Burnt Clay Building Bricks -Specification,” 1988.

[11] S. Safinia and A. Alkalbani, "Use of recycled plastic water bottles in concrete blocks," Procedia Eng., vol. 164, no. June, pp. 214-221, 2016.

[12] V. Gregorova, M. Ledererova, and Z. Stefunkova, "Investigation of Influence of Recycled Plastics from Cable, Ethylene Vinyl Acetate and Polystyrene Waste on Lightweight Concrete Properties," Procedia Eng., vol. 195, pp. 127-133, 2017.

[13] T. Qiu, H. Yan, J. Li, Q. Liu, and G. Ai, "Response surface method for optimization of leaching of a low-grade ionic rare earth ore," Powder Technol., vol. 330, no. 2017, pp. 330-338, 2018.

[14] I. M. Yusri, A. P. P. Abdul Majeed, R. Mamat, M. F. Ghazali, O. I. Awad, and W. H. Azmi, "A review on the application of response surface method and artificial neural network in engine performance and exhaust emissions characteristics in alternative fuel," Renew. Sustain. Energy Rev., vol. 90, no. November 2017, pp. 665-686, 2018. 